\section{0 ano de 2014 foi vitorioso para os pesquisadores e para a Revista Brasileira de Atividade Física e Saúde}

Alex Antonio Florindo

$\mathrm{O}$ ano de 2014 foi vitorioso para os pesquisadores da área de atividade física e saúde no Brasil. Primeiro, nós conseguimos organizar com êxito o V Congresso Mundial de Atividade Física e Saúde Pública na cidade do Rio de Janeiro no mês de abril. Neste que é considerado o principal evento mundial da área, nós conseguimos reunir mais de 700 participantes, sendo mais de 500 congressistas de outros países que apresentaram 554 trabalhos. Outro fato importante foi a realização do II Curso de Atividade Física e Saúde Pública para pesquisadores brasileiros organizado pela Sociedade Brasileira de Atividade Física e Saúde na cidade de Ipojuca, na bela região de Porto de Galinhas no mês de outubro de 2014. Conseguimos reunir durante sete dias mais de 30 pesquisadores, somando-se alunos e professores, os quais discutiram intensamente por mais de 40 horas diversos aspectos relacionados a área de atividade física e saúde. Os eventos regionais também foram extremamente importantes em 2014. A Sociedade Brasileira de Atividade Física e Saúde apoiou eventos que foram realizados nas regiões Sudeste, Nordeste, Sul, Centro-Oeste e Norte ${ }^{1}$. Isto corrobora o crescimento exponencial desta área no Brasil, fato que foi constatado em artigo publicado recentemente no volume de número cinco do nosso periódico sobre a produção científica em atividade física e saúde no nosso país ${ }^{2}$. Os resultados mostraram que a produção de artigos científicos de pesquisadores brasileiros em bases indexadas na área de atividade física e saúde cresceu de sete artigos publicados por ano em 2005 para 49 artigos publicados por ano em 2013, colocando o Brasil como um dos países importantes na produção do conhecimento mundial nesta área. E falando em publicações, consideramos que o ano de 2014 também foi extremamente importante para a Revista Brasileira de Atividade Física e Saúde. Nós tivemos 230 artigos submetidos, conseguindo superar o número de 222 artigos em 2013. Nós publicamos 74 artigos científicos, dos quais 59 foram originais, 10 foram de revisão, e cinco foram publicados nas seções especiais de experiências curriculares inovadoras e do diagnóstico à ação. Em relação às tramitações dos artigos, demoramos em média cerca de quatro meses entre a submissão e publicação dos artigos em 2014, fato muito importante e em minha opinião uma das principais virtudes da nossa revista que vem se mantendo desde que a Sociedade Brasileira de Atividade Física e Saúde assumiu a coordenação do periódico no ano de 2008, processo que foi liderado pelo Professor Pedro Curi Hallal como Editor-Chefe e pelo nosso grande mestre, o Professor Marcus Vinícius Nahas, que foi o primeiro presidente da Sociedade $^{3}$. Nestes seis anos, nós avançamos colocando a revista em dia, subimos de três para quatro volumes publicados de 2009 para 2010 e de quatro para seis volumes de 2011 para 2012. No ano de 2012, nós aumentamos o número de editores, conseguimos auxílio para publicação de um edital proposto em conjunto pelo Ministério da Ciência e Tecnologia, Ministério da Educação, Conselho Nacional de Desenvolvimento Científico e Tecnológico e Comissão
Rev Bras Ativ Fis Saúde p. 665-666 DOI

http://dx.doi.org/10.12820/rbafs.v.19n5p665

Editor-Chefe da Revista Brasileira de Atividade Física e Saúde 
de Aperfeiçoamento de Pessoal do Nível Superior e implantamos a plataforma eletrônica, colocando um novo ISSN eletrônico para a revista, bem como a identificação dos artigos pelo Digital Object Identifier. Todo o detalhamento desta evolução foi descrito em publicação recente liderada pelo Professor Mauro Barros ${ }^{4}$ (que foi um dos nossos grandes editores!). Apesar de toda esta evolução que nos coloca como um periódico importante dentro da área de Educação Física contemplando verdadeiramente o escopo da área de atividade física e saúde no Brasil, nós ainda temos muito que melhorar. Pensando nisso, estamos projetando a internacionalização da nossa revista para 2015. Queremos evoluir convidando editores internacionais para compor o nosso quadro, incentivar os autores para submeterem artigos em inglês e continuar oferecendo traduções profissionais para os artigos aceitos. Vale ressaltar que em 2014, $12 \%$ dos nossos artigos originais foram publicados em inglês. Queremos subir muito este índice em 2015. Além disso, procuraremos manter a nossa principal virtude que são as revisões rápidas, nos esforçar para manter as publicações em dia e buscar a indexação do periódico em bases importantes como a Scielo e PubMed. Para finalizar e como já é tradicional e algo muito saudável na nossa revista, no ano de 2015 nós teremos mudanças no quadro dos editores nacionais. Eu estou saindo do quadro dos editores-chefes e teremos a inclusão de um novo editor-chefe e de novos editores associados. Agradeço aos Professores José Cazuza de Farias Junior e Airton José Rombaldi por compartilharem comigo as amarguras e felicidades no convívio da editoria durante todo este tempo, bem como a todos os editores-associados, revisores e autores da área de atividade física e saúde. Sem vocês todos, certamente não teríamos chegado aonde chegamos! Finalizando, o ano de 2015 se projeta como desafiador para a área e para a revista, pois sabemos que não é fácil manter um periódico científico com qualidade no Brasil. Mas com o apoio de toda a comunidade da área de atividade e saúde, eu acredito que será "ripa na chulipa”, como dizia o grande locutor esportivo Osmar Santos para incentivar os times de futebol a atacarem e vencerem! Vamos em frente para continuar crescendo em 2015!

\section{REFERÊNCIAS}

1. Rech CR, Loch MR, Gonçalves PB, Hino AFA, Reis RS. Simpósios Regionais de Atividade Física e Saúde: um grande marco do ano de 2014! Revista Brasileira de Atividade Física \& Saúde. 2014; 19 (Suplemento 1):1-124.

2. Ramires VV, Becker LA, Sadovsky ADI, Zago AM, Bielemann RM, Guerra PH. Evolução da pesquisa epidemiológica em atividade física e comportamento sedentário no Brasil: atualização de uma revisão sistemática. Revista Brasileira de Atividade Física \& Saúde. 2014; 19(5):529-530.

3. Hallal PC. Do diagnóstico à ação: a promoção da atividade física como prioridade em saúde. Revista Brasileira de Atividade Física \& Saúde. 2008; 13(1):1.

4. Barros MVG; Rombaldi AJ, Borges TT, Florindo AA. Revista Brasileira de Atividade Física \& Saúde: experiências e processos editoriais. Revista Brasileira de Ciências do Esporte. 2014;36(4):746-751.

ENDEREÇO PARA

CORRESPONDÊNCIA

Escola de Artes, Ciências e

Humanidades da Universidade de

São Paulo

Rua Arlindo Bettio, 1000 ,

Ermelino Matarazzo, São Paulo, SP.

CEP: 03828-000

E-mail: aflorind@usp.br 